\title{
Cogging torque in slotless permanent magnet machines
}

\author{
Mario Vukotić ${ }^{*}$, Danijel Rodić ${ }^{2}$ Boris Benedičič ${ }^{2}$, Damijan Miljavec $^{1}$
}

\begin{abstract}
Slotless permanent magnet machines theoretically do not produce any cogging torque, provided the stator inner surface reluctance remains unchanged. However, a cogging torque may occur due to a change in the electromagnetic design following material cost reduction in the manufacturing process. When the electromagnetic design is changed to reduce the waste in the manufacturing process (stamping of the laminations) by dividing the stator toroidal ferromagnetic core into two equal parts, gluing them together introduces a very small non magnetic gap between them, which affects the stored magnetic energy along the circumference and consequently gives rise to occurrence of a cogging torque. Using the finite element method its value is analyzed analytically and verified by a laboratory measurement. Results of our work, presented in this paper, will help scientists and engineers to understand and avoid the causes for the occurrence of the cogging torque in designing slotless permanent magnet machines, where the design itself is subjected to the manufacturing process.
\end{abstract}

K e y w or ds: cogging torque, slotless permanent-magnet machines, manufacturing process

\section{Introduction}

The European legislation imposed on the manufacturers of household electric devices requires the minimization of electric energy consumption. This means that the energy efficiency of a device must be increased as much as possible. Thus, all of its components (eg electric motor, as one of them) have to be as efficient as possible. At the same time, their cost has to be minimized due to the price pressure from the market. Efficiency improvement and cost minimization motivate the manufacturers to increase the motor rotational speed, minimize its total weight and optimize the cost of its manufacturing process. When the rotational speed of a motor enters the area of ultra high speeds (above 60000/min), various electromagnetic designs need to be considered, one such being the slotless permanent magnet (PM) machine [1 4]. Generally, the slotless PM machine is used in applications with a very small or zero torque pulsation [5 11], such as hard disk drives, servo drives, sensitive medical equipment, spacecraft applications, etc. As in these applications there is no interaction between PM and the stator teeth (there are none), and the torque ripple is almost zero due to the absence of higher harmonic components in the air gap PM magnetic flux density, thus there is no cogging torque either [12 17].

The focus of our paper is on the differences between the theoretical and practical approaches to solving the issue of the cogging torque occurrence in slotless PM machines. A cogging/detent force in a slotless linear motor is reported in $[18,19]$. Here, it is a consequence of the finite length of the mover and cannot happen in a rotary machine. Although, theoretically, the cogging torque cannot exist in a rotating slotless machine, it is detected on the real machine prototype. In this paper, we explain why this happens and how to avoid it.

The structure of the studied slotless PM machine is simple, Fig. 1. The rotor consists of a ferromagnetic shaft and cylindrical

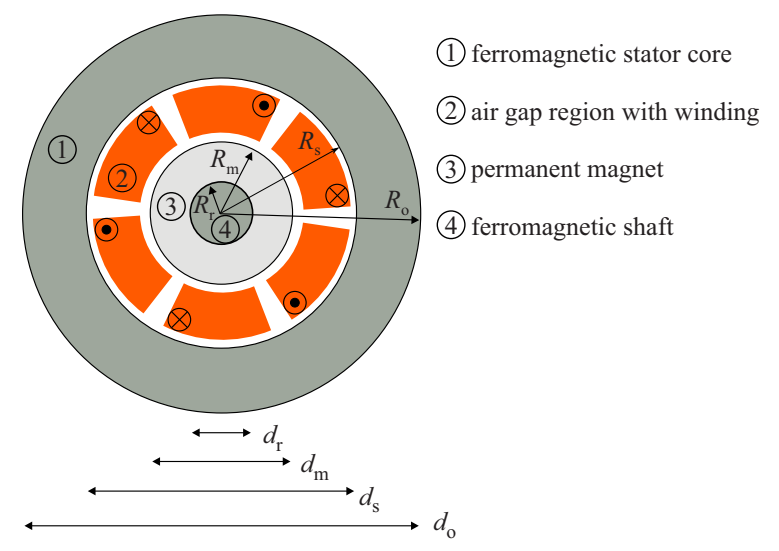

Fig. 1. Machine structure with the main dimensions

PM (bonded NdFeB), surrounded with a sleeve made of a glass fiber (electrically and magnetically non conductive material) to protect the rotor against mechanical damages that may occur because of the centrifugal force. To reduce the waste of the lamination material in the manufacturing process (stamping of the laminations) and consequently the price of the motor, the stator core is built from two equal ferromagnetic $\mathrm{C}$ shaped halves, glued together into a toroid (Fig. 5). For a household application glue will ensure enough strength to keep the halves together. Between the rotor and stator, a three phase winding is placed. It is not drawn in the figures in the paper, apart from Fig. 1, for playing no role resulting

\footnotetext{
${ }^{1}$ University of Ljubljana, Faculty of Electrical Engineering, Tržaška cesta 25, Ljubljana, Slovenia, ${ }^{2}$ Domel, Otoki 21, Železniki, Slovenia, ${ }^{*}$ Corresponding author: mario.vukotic@fe.uni-lj.si
} 
in a cogging torque. Other non magnetic parts (ceramic bearings, plastic housing etc.) with no impact on the cogging torque are not drawn either.

Two possible causes for the cogging torque in the slotless PM machine, identified by the authors, are the rotor eccentricity and the air gap between the stator halves. They are both associated with and affected by the manufacturing process. In this paper, they will be referred to as manufacturing irregularities:

- rotor eccentricity: a rotor is eccentric, when it is closer to one side of the stator than to the side that is diametrically opposite to it [20];

- air gap between the stator halves: such air gap is inevitable. It is caused by gluing the stator halves together.

The manufacturing irregularities that are likely to affect the stored magnetic energy in the overall machine structure during the rotor rotation and which manifest themselves in a cogging torque are analyzed and (FEA) of the cogging torque supported by a measurement is given.

\section{Theoretical analysis}

First, it must be determined which of the two manufacturing irregularities gives rise to a cogging torque and to what extent. The general equations to calculate the flux density are given in Section 2.1. They are used to calculate the magnetic energy stored in the system. There are two different areas for which the magnetic energy is calculated. When calculating the cogging torque caused by the eccentricity, the magnetic energy stored in the air gap and PM is considered. When calculating the cogging torque caused by the air gap between the stator halves, the magnetic energy stored in the air gap and to a lesser extent also outside the stator core (Fig.6) is considered. The magnetic energy stored in the air gap between the stator and rotor is not considered when calculating the cogging torque because it is constant during rotor rotation. Its (negative) derivative is zero (10).

In each calculation, only one manufacturing irregularity is considered at a time in order to exclude the impact of the other. Table 1 shows the main machine data of the prototype used in the analysis.

\subsection{Calculation of the flux density}

Our 2D analytical analysis of the cogging torque is made on basis of the following assumptions:

- Permeability of the ferromagnetic parts, ie the stator core and shaft, can be treated as infinite due to the low flux density (less than $0.4 \mathrm{~T}$ in the toroidal stator core and shaft), Fig. 2;

- Calculation of the magnetic energy in the air gap between the stator halves, Fig. 5:

(i) Uniform magnetic flux distribution in the air gap and a negligible fringing effect between the $\mathrm{C}$ shaped stator halves; (ii) Magnetic energy stored in the air gap is constant. The variable part of the stored energy comes from the air gap between the stator halves and leakage magnetic flux outside the stator core;

(iii) Negligible end-effect on the axial sides of the machine.

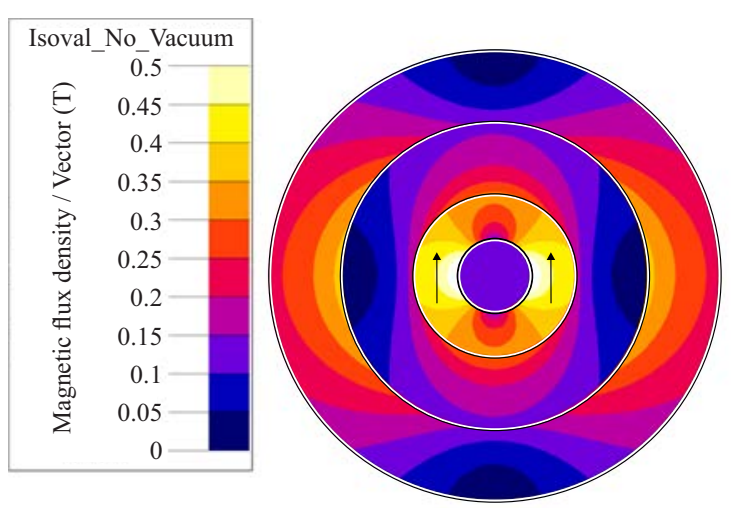

Fig. 2. Flux density distribution of a machine with full toroidal stator and centered rotor

The procedures to calculate the flux density in the air gap and PM are described in [21-23] for different magnetization patterns. However, in our case, the most appropriate equations for the radial and tangential component of the flux density $B_{r}$ and $B_{\theta}$, respectively) valid for the ring magnet with a parallel magnetization pattern in the air gap (area I) and PM (area II) is given in [24],see (1)-(4). In the equations, the variables $r$ and $\theta$ are the coordinates of an arbitrary point in the air gap and PM, and $\theta_{0}$ is the rotor position. The total flux density in the air gap and permanent magnet area is calculated as follows, denoting

$$
\begin{aligned}
& \lambda_{\mathrm{rm}}=\left(\frac{R_{\mathrm{r}}}{R_{\mathrm{m}}}\right)^{2}, \lambda_{\mathrm{sm}}=\left(\frac{R_{\mathrm{s}}}{R_{\mathrm{m}}}\right)^{2}, \\
& \lambda_{\mathrm{s}}(r)=\left(\frac{R_{\mathrm{s}}}{r}\right)^{2}, \lambda_{\mathrm{r}}(r)=\left(\frac{R_{\mathrm{r}}}{r}\right)^{2}, \\
& \text { and } \\
& D_{0}=\left(1-\lambda_{\mathrm{rm}}\right)\left(1+\lambda_{\mathrm{sm}}\right), \\
& D=D_{0}-\mu_{r}\left(1-\lambda_{\mathrm{sm}}\right)\left(1+\lambda_{\mathrm{rm}}\right),
\end{aligned}
$$

$$
\begin{gathered}
B_{r I}\left(r, \theta, \theta_{0}\right)=\frac{\left(1-\lambda_{\mathrm{rm}}\right)(1+\lambda(r))}{D} B_{r} \cos \left(\theta-\theta_{0}\right), \\
B_{\theta I}\left(r, \theta, \theta_{0}\right)=-\frac{\left(1-\lambda_{\mathrm{rm}}\right)(1-\lambda(r))}{D} B_{r} \sin \left(\theta-\theta_{0}\right), \\
B_{r I I}\left(r, \theta, \theta_{0}\right)=\frac{K_{r}(r)}{D} B_{r} \cos \left(\theta-\theta_{0}\right) \\
K_{r}(r)=D_{0}-\mu_{\mathrm{r}}\left(1-\lambda_{\mathrm{sm}}\right),\left[\lambda_{\mathrm{rm}}-\lambda_{\mathrm{r}}(r)\right] \\
B_{\theta I I}\left(r, \theta, \theta_{0}\right)=\frac{K_{\theta}(r)}{D} B_{r} \sin \left(\theta-\theta_{0}\right) \\
K_{\theta}(r)=-D_{0}+\mu_{\mathrm{r}}\left(1-\lambda_{\mathrm{sm}}\right),\left[\lambda_{\mathrm{rm}}+\lambda_{\mathrm{r}}(r)\right]
\end{gathered}
$$




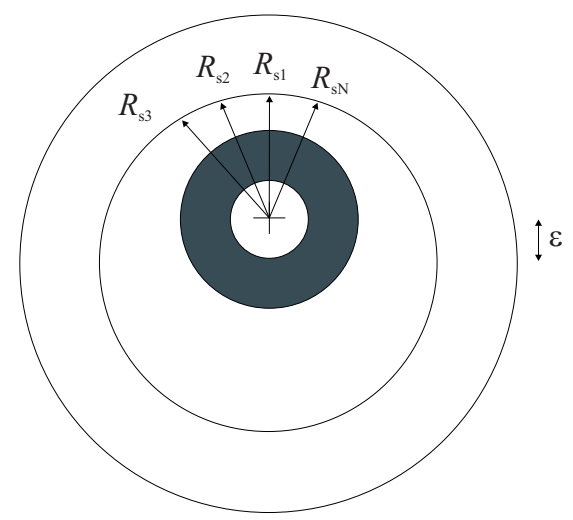

Fig. 3. Distances between the rotation center and the stator core of an eccentric rotor

Table 1. Machine data

\begin{tabular}{lcc}
\hline Quantity & Symbol & Value \\
Nominal torque & $T-n$ & $30 \mathrm{mNm}$ \\
Number of pole pairs & $p$ & 1 \\
Shaft diameter & $d_{\mathrm{r}}$ & $8 \mathrm{~mm}$ \\
Rotor/magnet outer diameter & $d_{\mathrm{m}}$ & $18 \mathrm{~mm}$ \\
Stator inner diameter & $d_{\mathrm{s}}$ & $34 \mathrm{~mm}$ \\
Stator outer diameter & $d_{\mathrm{o}}$ & $50 \mathrm{~mm}$ \\
Axial length of the active part & $l_{a}$ & $25 \mathrm{~mm}$ \\
Remanent flux densityq & $B_{\mathrm{r}}$ & $0.60 \mathrm{~T}$ \\
PM relative permeability & $\mu_{\mathrm{r}}$ & 1.1 \\
PM magnetization pattern & $/$ & parallel \\
Number of stator segments & $N_{\mathrm{seg}}$ & 2 \\
Stator core material & $/$ & M270 35A \\
\hline
\end{tabular}

$$
\begin{gathered}
B_{I}^{2}=B_{r I}^{2}+B_{\theta I}^{2}, \\
B_{I I}^{2}=B_{r I I}^{2}+B_{\theta I I}^{2} .
\end{gathered}
$$

These equations are used: (a) to calculate the cogging torque caused by the eccentricity; they are used directly to calculate the stored magnetic energy, and (b) to calculate the cogging torque caused by air gap between the stator halves; they are used to calculate the magnetic flux entering the stator core. Later, this magnetic flux will be used to calculate the stored magnetic energy in the air gap between the stator halves.

\subsection{Calculation of the cogging torque caused by eccen- tricity}

To calculate the cogging torque caused by the eccentricity, the stator is modelled as a toroid with no air gap (whole toroid) and the eccentricity is extremely exaggerated. The rotation center is moved $5 \mathrm{~mm}(\varepsilon)$ upward from the center of the stator coordinate system (Fig. 3).

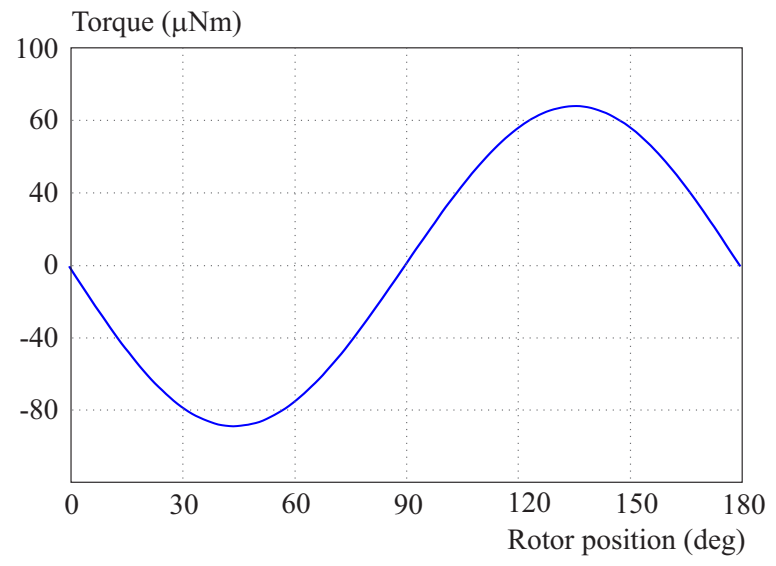

Fig. 4. Non-zero cogging torque because of a numerical error (2DFEA)

In such system, the stored magnetic energy is obtained as an average value of $\mathrm{N}$ calculations of the magnetic energy for the stator inner radius $\left(R_{s}\right)$ which is different for each calculation [25], Fig. 3. Due to the PM linear permeability (area I) and air gap (area II), the magnetic energy in each area at a certain rotor position $\theta_{0}$ is expressed as

$$
\begin{gathered}
W_{m_{I}}\left(\theta_{0}\right)=l_{a} \int_{R_{m}}^{R_{s}} \int_{0}^{2 \pi} r \frac{B_{I}\left(r, \theta, \theta_{0}\right)^{2}}{2 \mu} \mathrm{d} \theta \mathrm{d} r \\
W_{m_{I} I}\left(\theta_{0}\right)=l_{a} \int_{R_{r}}^{R_{m}} \int_{0}^{2 \pi} r \frac{B_{I I}\left(r, \theta, \theta_{0}\right)^{2}}{2 \mu} \mathrm{d} \theta \mathrm{d} r .
\end{gathered}
$$

The total stored magnetic energy is the sum of both energies, $W_{m_{I}}$ and $W_{m_{I I}}$

$$
W_{m}\left(\theta_{0}\right)=W_{m_{I}}\left(\theta_{0}\right)+W_{m_{I I}}\left(\theta_{0}\right)
$$

The cogging torque is calculated as a negative derivative of the total stored energy at the rotor position $\theta_{0}[26,27]$

$$
T_{\mathrm{c}}\left(\theta_{0}\right)=\frac{\mathrm{d} W_{m}\left(\theta_{0}\right)}{\mathrm{d} \theta_{0}}
$$

The cogging torque in the analytically obtained result is zero (no energy variation during the rotor rotation) despite a considerable eccentricity. However, the 2D FEA numerical result given in Fig. 4 shows a low amplitude of the sinusoidal torque shape. A further analysis reveals the difference between the analytical and the 2D FEA result. The sinusoidal torque shape is a consequence of the finite number of the mesh elements (discretization of the space). If their number increases, the amplitude of the calculated sinusoidal torque decreases. The lowest amplitude obtained by increasing their number is $65 \times 10^{-6}$ $\mathrm{mNm}$. It is about $10^{9}$ times smaller than the nominal torque, thus proving the analytical result is correct. 


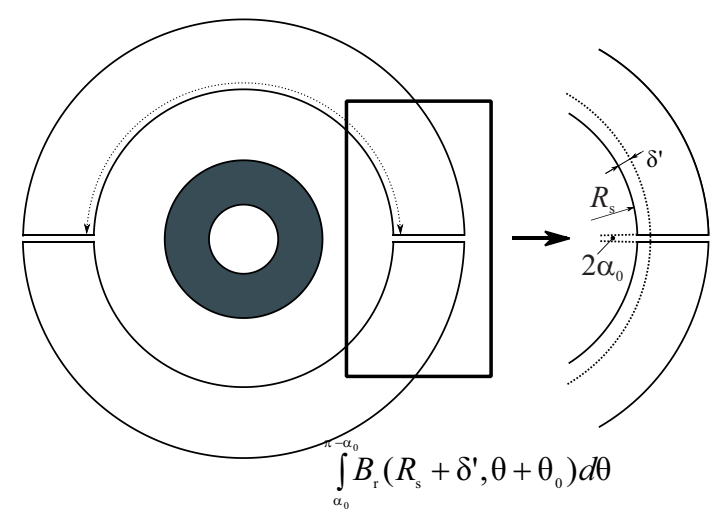

Fig. 5. Integration path for the flux calculation

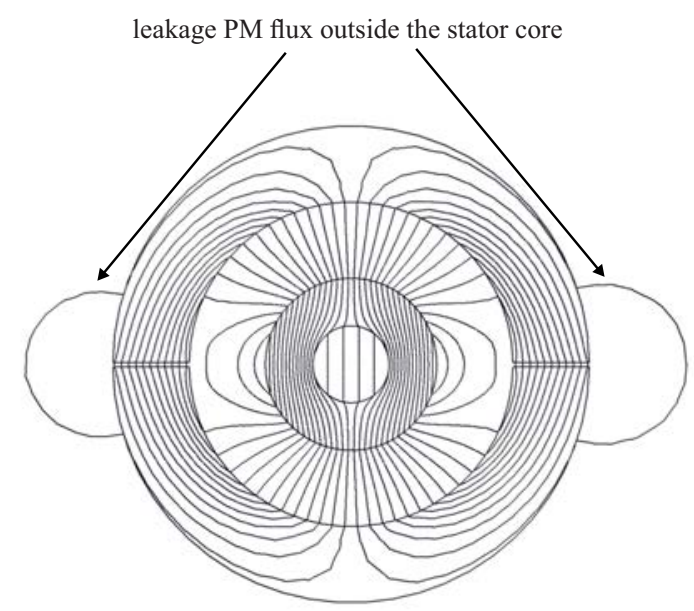

Fig. 6. Magnetic flux lines with an air gap between stator halves

\subsection{Calculation of the cogging torque caused by an air gap between stator halves}

To calculate the cogging torque caused by an air gap between stator halves, the rotor is positioned in the center of the coordinate system (Fig. 5). To calculate the magnetic flux analytically, the stator inner radius $\left(R_{\mathrm{s}}\right)$ is virtually increased for the weighted width of the air gap between the stator halves $(\delta)$, ie the ratio between the arc length of one stator half and the air gap width, and the stator is assumed to be a full toroid. The width $(\delta)$ changes while the rotor rotates because the magnetic flux crossing the air gap changes continuously as a function of the rotor magnetic flux. The two possible extreme situations are: (a) when the PM magnetic polarization is aligned with the air gap, the magnetic flux does not cross it, and (b) when the PM magnetic polarization is perpendicular to the air gap, the magnetic flux crosses it. Equations (11) and (12) describe the continuous changing of the width $(\delta)$

$$
\begin{gathered}
\delta^{\prime}\left(\theta_{0}\right)=\frac{\delta_{0}}{2}(1+\underbrace{\sin \left(N_{\mathrm{seg}} \theta_{0}\right)}_{\text {changing part }} \underbrace{\frac{2\left(\pi-\alpha_{0}\right)}{N_{\text {seg }}\left(R_{\mathrm{o}} / R_{\mathrm{s}}-1\right)}}_{\text {weighted widt }}, \\
\alpha_{0}=\arcsin \left(\frac{\delta / 2}{R_{\mathrm{s}}}\right),
\end{gathered}
$$

where $\delta_{0}$ is the actual (physical) air-gap width and $\alpha_{0}$ is a half of the opening angle between the air gaps between the stator halves.

To calculate the magnetic energy stored in the air gap, the flux density at the inner stator radius, virtually increased by $\delta^{\prime}$, is calculated using (1), where

$$
r=R_{\mathrm{s}}^{\prime}=R_{\mathrm{s}}^{\prime}+\delta^{\prime}
$$

Considering the boundary conditions for the normal component of the magnetic flux density $\left(B_{\mathrm{n}}\right)$ and tangential component of the magnetic intensity $\left(H_{\mathrm{t}}\right)$ between the air gap and stator core (indices 1 and 2, respectively), $B_{\mathrm{n} 1}=B_{\mathrm{n} 2}$ and $H_{\mathrm{t} 1}=H_{\mathrm{t} 2}$, and assuming the infinite permeability of the stator core $\left(\mu_{\mathrm{r}, \mathrm{Fe}} \rightarrow \infty\right)$, it can be concluded that at the inner stator radius, there is only the normal component of the magnetic flux density $\left(B_{\mathrm{n}} \neq 0\right.$ and $\left.B_{\mathrm{t}}=0\right)$, thus only (1) is used. The total flux $(\Phi)$ passing the air gap between the stator halves is obtained with integration through one segment at radius $R_{\mathrm{s}}^{\prime}$

$$
\Phi\left(\theta_{0}\right)=\sigma l_{a} R_{\mathrm{s}} \int_{\alpha_{0}}^{\pi-\alpha_{0}} B_{r}\left(R_{\mathrm{s}}^{\prime}, \theta, \theta_{0}\right) \mathrm{d} \theta .
$$

Coefficient $\sigma$ is the magnetic coupling, ie the ratio between the magnetic flux, passing the air gap between the stator halves, and the magnetic flux, entering the stator core at the stator inner radius $\left(R_{\mathrm{s}}\right)$. The magnetic flux, passing the air gap between the stator halves, is smaller than the magnetic flux entering the stator core because some of the magnetic flux passes the air outside the stator core when the air gap between the stator halves is accounted for (Fig. 6).

To calculate coefficient $\sigma$, an appropriate length of the magnetic path is used. In Fig. 7, the parameter $s$ represents the arc which is half of the total magnetic path. The center of the arc is in point $\mathrm{S}$ whose coordinates are obtained from known point $\mathrm{T}$. This is due to the fact that the magnetic flux leaves the stator core perpendicularly to the surface because of the same boundary conditions and very high permeability, as above.

The value of the $x_{0 T}$ coordinate of point $\mathrm{T}$ is in interval $\left[0, R_{0}\right]$ and $y_{\mathrm{T}}=\sqrt{R_{0}^{2}-x_{\mathrm{T}}^{2}}$. The linear and constant coefficient of the line connecting points $\mathrm{T}$ and $\mathrm{S}$ are

$$
k=-\frac{x_{\mathrm{T}}}{y_{\mathrm{T}}}, \quad n=\frac{R_{0}^{2}}{y_{\mathrm{T}}},
$$

giving the coordinates of the point $\mathrm{S}$

$$
X_{\mathrm{S}}=\frac{R_{0}^{2}}{x_{\mathrm{T}}}, \quad y_{\mathrm{S}}=0
$$




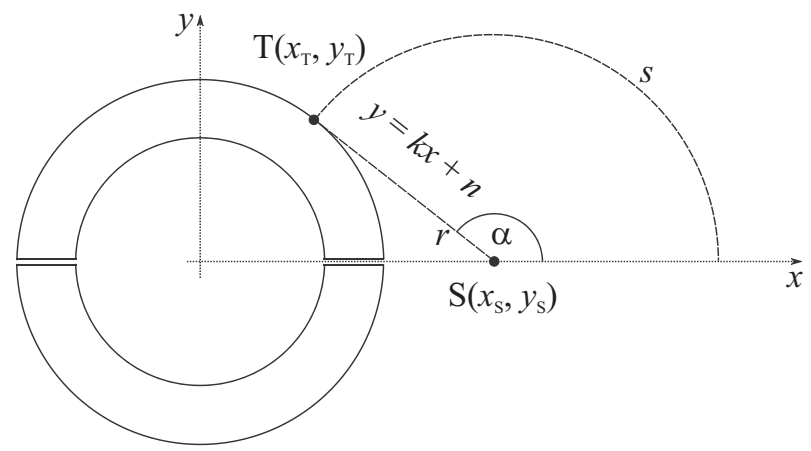

Fig. 7. Calculation of the path $s$

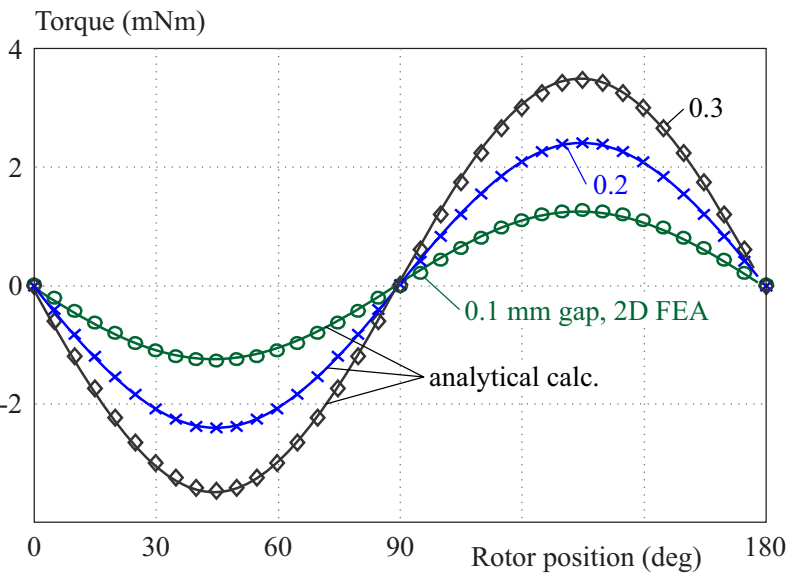

Fig. 9. Cogging torque caused by an air gap between the stator halves (analytical and 2D FEA calculation)
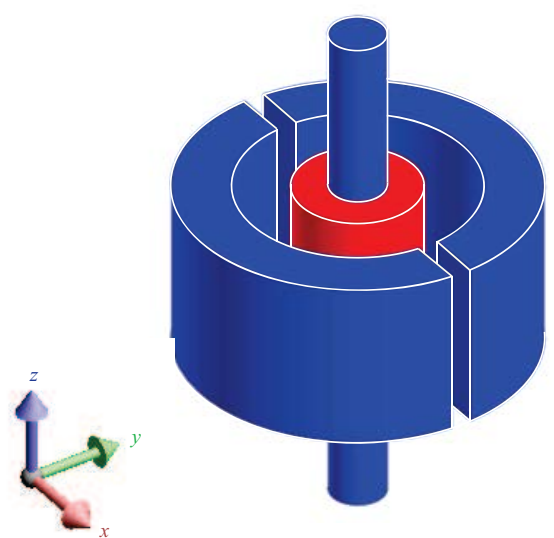

Fig. 11. 3D FEA model for the cogging torque calculation with increased air gap between stator halves to $5 \mathrm{~mm}$ for a better visualization

The arc length $(s(r))$ representing the leakage flux line is obtained from Fig. 7

$$
\begin{gathered}
r=\sqrt{\left(x_{\mathrm{S}}-x_{\mathrm{T}}\right)^{2}+\left(y_{\mathrm{S}}-x_{\mathrm{T}}\right)^{2}}=R_{0} \frac{y_{\mathrm{T}}}{x_{\mathrm{T}}}, \\
\alpha=\pi+\arctan \left(-\frac{x_{\mathrm{T}}}{y_{\mathrm{T}}}\right)=\pi-\arctan \frac{R_{0}}{r}, \\
s(r)=r \alpha=r\left(\pi-\arctan \frac{R_{0}}{r}\right) .
\end{gathered}
$$

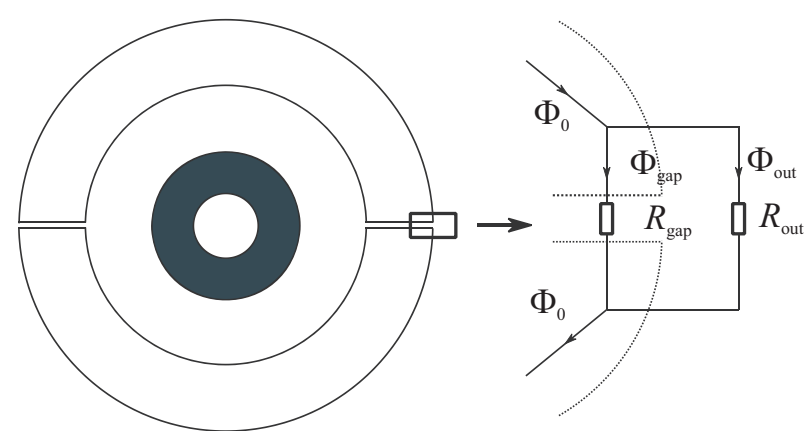

Fig. 8. Magnetic flux dividing for calculation of $\sigma$

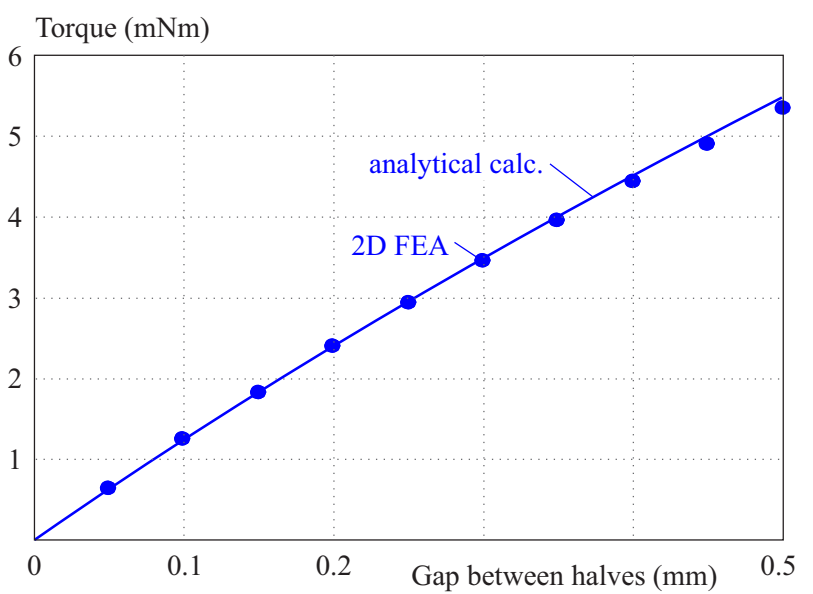

Fig. 10. Comparison between the analytical and 2D FEA calculation of the cogging torque

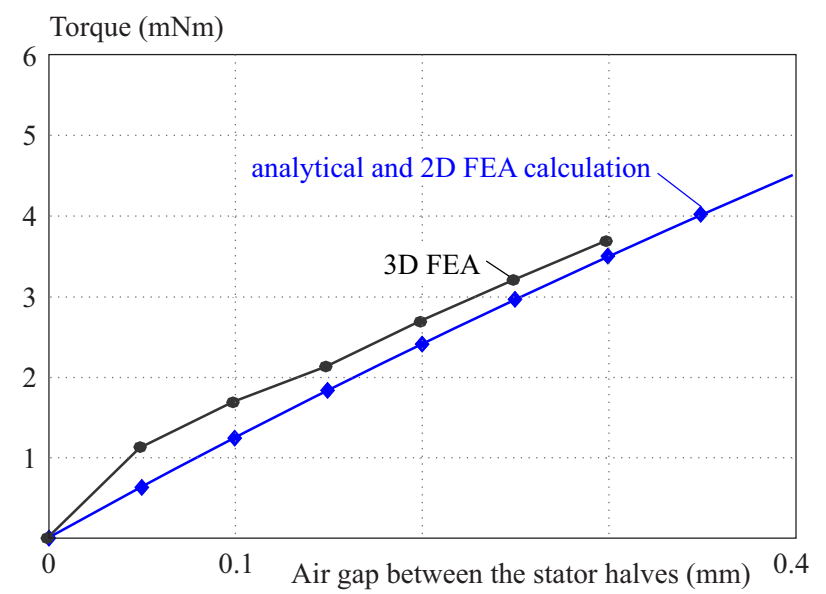

Fig. 12. Cogging torque amplitude $v s$ the air gap between the stator halves (2D and 3D FEA)

The magnetic coupling coefficient is calculated as

$$
\sigma=\frac{1}{1+R_{\text {gap }} / R_{\text {out }}},
$$

where

$$
R_{\text {out }}^{-1}=\mu_{0} l_{\alpha} \int_{\delta_{0} / 2}^{\infty} \frac{\mathrm{d} r}{2 s(r)}
$$




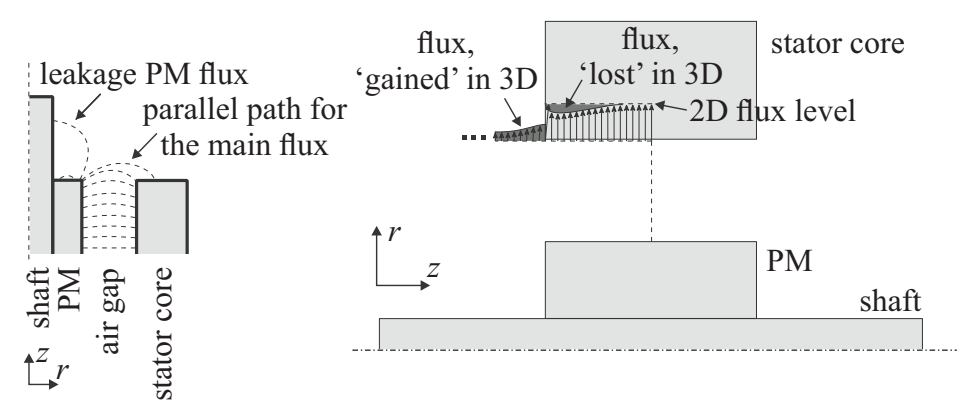

Fig. 13. Parallel path for the main magnetic flux in the axial cross section
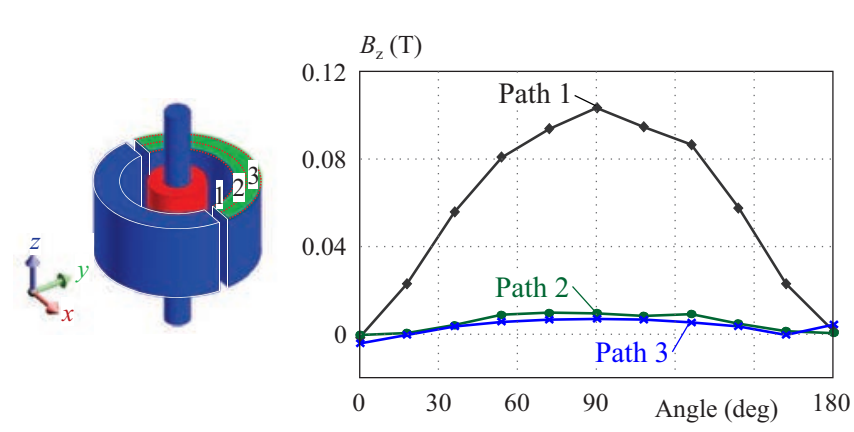

Fig. 14. Calculation of axial magnetic flux density: (a) - paths 1,2 and 3 on the side surface of the stator core and (b) $-z$-component of magnetic-flux density on these paths (a) - flux lines and (b)axial cross section of the 3D model with flux differences between $2 \mathrm{D}$ and $3 \mathrm{D}$ model

The values of the magnetic coupling coefficient $\sigma$ for small values of $\delta_{0}$ are high (0.98 or more for an air gap width below $0.3 \mathrm{~mm}$ ).

The air gap width varies between $0.1 \mathrm{~mm}$ and $0.3 \mathrm{~mm}$. The results are presented in Fig. 9 and Fig. 10. The analytical result matches with $2 \mathrm{D}$ FEA calculation quite well due to high permeability of the ferromagnetic parts (assumed infinite in analytical calculations). The maximum difference between them is less than $2 \%$. The amplitudes of the cogging torque vary from $1.25 \mathrm{mNm}$ to $3.47 \mathrm{mNm}$ for a $0.1 \mathrm{~mm}$ and $0.3 \mathrm{~mm}$ air gap width, respectively. This represents a relatively large torque pulsation compared to the nominal torque (from $4.2 \%$ to $11.6 \%$ ) and confirms that the air gap between the stator halves is the reason for the cogging torque occurrence. The magnetic energy in the air gap between the stator halves as a function of the rotor position is

$$
W_{m}\left(\theta_{0}\right)=\frac{1}{2} B H V=\frac{B^{2}}{\mu_{0}} V=\frac{\left(\frac{\Phi\left(\theta_{0}\right)}{2 a l_{a}}\right)^{2}}{2 \mu_{0}}\left(2 a l_{a} \delta_{0}\right) .
$$

\section{Calculation and measurement}

To obtain a more accurate value of the cogging torque for a given machine, the 3DFEA model (Fig. 11) is built that considers both the fringing effect and PM axial leakage flux. Neither of them can be neglected because of the
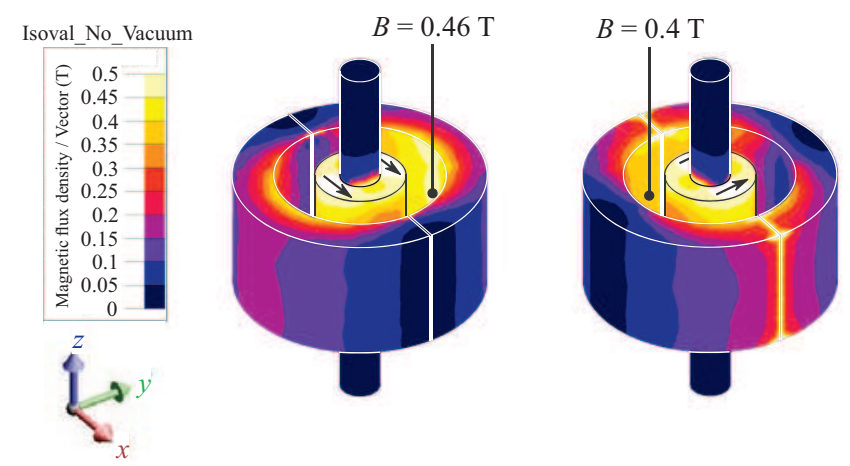

Fig. 15. Magnetic flux density in the machine: (a) - the rotor magnetization aligned with the air gap between stator halves (zero cogging torque), and (b) - is perpendicular to it (peak value of the cogging torque)

considerable air gap width compared to the machine axial length [12], [28]. To allow for a better visualization, in the model in Fig. 11, the air gap between the stator halves is increased to $5 \mathrm{~mm}$.

Generally, calculating the cogging torque using the FEA may cause an error originating from the calculation method itself, ie remeshing the model with a changing rotor position [26], [29]. By keeping the rotor mechanically locked and the PM magnetization direction rotated [30], the calculation accuracy is significantly improved. The 3D FEA amplitudes of the cogging torque though expected to be lower compared to the 2D FEA amplitudes due to the fringing effect and axial leakage, are in fact slightly higher (Fig. 12). The difference decreases with an increase in the width of the air gap between the stator halves. The reason for the higher values is the additional parallel path for the main magnetic flux (Fig. 13) which enters the stator core axially (green colored area in Fig. 14(a). Our analysis shows that this rather small additional magnetic flux, Fig. 14(b), cannot be neglected when calculating the total magnetic flux and stored magnetic energy.

At a high rotational speed, the magnetic flux may give rise to additional losses at high rotational speeds since it enters the laminations perpendicularly to the surface. However, this exceeds the scope of this paper. These results altogether confirm the necessity of using 3D FEA to calculate the properties of the slotless PM machines. 


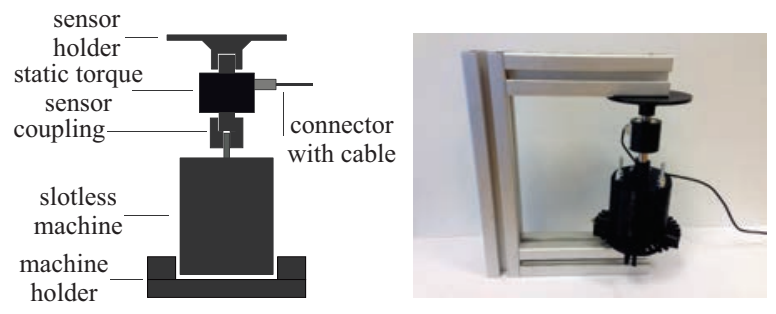

Fig. 16. Measurement setup:(a) sketch and (b) photo

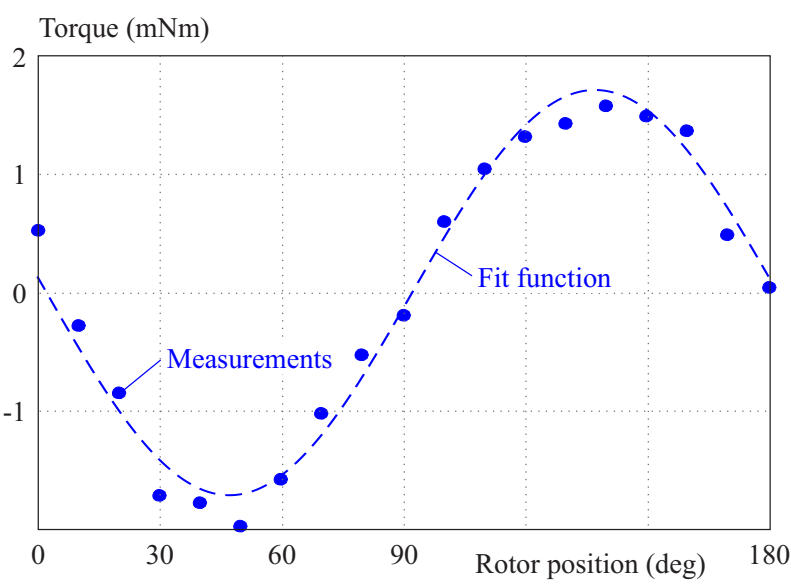

Fig. 17. Measurement results

To verify the 3D FEA calculation, a measurement setup is built (Fig. 16) and used to measure the cogging torque. It is a vertical setup with a static torque sensor fixed on its top and a machine placed on its bottom, so that the sensor does not carry any of the machine weight. The sensor and machine are connected via a coupling element enabling its movement in the vertical direction but the torque transfer in the tangential direction. The machine holder allows the angle positioning with a 10 (mechanical) step. The machine is equipped with high performance Zr ceramic bearings with negligible friction torque, thus cogging torque can be accurately measured.

The measurement results shown in Fig. 17 match with those obtained with the 3D FEA calculation. The shape of the measured cogging torque vs. the rotor angle is sinusoidal with some error present. By fitting the sinusoidal function $f(\theta)=A \sin (2 \theta+\varphi)$ to the measurement results, the following coefficients are obtained: $\mathrm{A}=1.71$ $\mathrm{mNm} ; \varphi=175.46^{\circ}$

The width of the air gap between the stator halves can be estimated from the amplitude of the fitted curve $(A)$ using the 3D FEA results (Fig. 12). The 3D FEA results are fitted with the lineaar function, valid for the air gap width between $0.05 \mathrm{~mm}$ and $0.3 \mathrm{~mm}, A(g)=(10 g+0.70)$ $\mathrm{mNm}$ where $g$ is the air gap width in $\mathrm{mm}$. The calculated average width of the air gap between the stator halves is $0.101 \mathrm{~mm}$ which is the expected glue thickness.

\section{Conclusion}

When subjected to a manufacturing process, an electromagnetic design of a machine may suffer from unexpected anomalies, such as experienced with the slotless PM machine, giving rise to a cogging torque occurrence, though theoretically non-existent.

The two main causes for the cogging torque occurrence are discussed, ie the rotor eccentricity and the air gap between the stator halves caused by the used glue. It is shown that the eccentricity does not affect the cogging torque in the slotless PM machines. The cause for the cogging torque is the stator toroid core divided into two C shaped halves with an inevitable air gap between them which affects the reluctance and, consequently, the stored magnetic energy and gives rise to the occurrence of the cogging torque.

The problem is analyzed using FEA (2D and 3D) and confirmed with a measurement on a real machine prototype. The presented methodology for calculating the cogging torque in slotless PM machines with segmented stator core allow its prediction and possibility to avoid it already in the design phase of the machine.

\section{Acknowledgements}

The authors acknowledge the project ID L2-8187 was financially supported by the Slovenian Research Agency. The authors would like to thank the company Domel for providing the necessary components to build the prototype.

\section{REFERENCES}

[1] N. Bianchi, S. Bolognani, and F. Luise, "Potentials and limits of high speed PM motors", IEEE Transactions on Industry Applications, 2004, vol. 40, no. 6, pp. 15701578 .

[2] N. Bianchi, S. Bolognani, and F. Luise, "Analysis and design of a PM brushless motor for high-speed operations", IEEE Transactions on Energy Conversion, 2005, vol. 20, no. 3, pp. 629637.

[3] N. Bianchi, S. Bolognani, and F. Luise, "High speed drive using a slotless PM motor", IEEE Transactions on Power Electronics, 2006, vol. 21, no. 4, pp. 10831090.

[4] O. Wallmark and P. Kjellqvist, "Analysis of a Low-Cost Air-Gap Winding for Permanent Magnet Synchronous Motors", IEEE Transactions on Energy Conversion, 2009, vol. 24, no. 4, pp. 841847.

[5] T. S. Low, T. A. Jabbarand, and T. S. Tan, "Design aspects and performance of a slotless PM motor for hard disk drives", IEEE Industry Applications Magazine, 1997, vol. 3, no. 6, pp. 4351.

[6] D. Lee, A. Jin, and B. Min, "Optimisation method to maximise torque density of high-speed slotless permanent magnet synchronous machine aerospace applications", IET Electric Power Applications, 2018, vol. 12, no. 8, pp. 10751081.

[7] H. Lee, E. Lee, S. Kwon et al, "A Study on Brushless PM Slotless Motor with Toroidal Winding", 2017 IEEE International Electric Machines and Drives Conference (IEMDC), Miami, FL, USA, May 2017, pp. 16.

[8] R. P. Praveen, M. H. Ravichandran, V. T. S. Achari et al, "A Novel Slotless Halbach-Array Permanent-Magnet Brushless DC Motor for Spacecraft Applications", IEEE Transactions on Industrial Electronics, 2012, vol. 59, no. 9, pp. 35533560. 
[9] P. Puentener, M. Schuck, D. Steinert et al, "A 150000-r/min bearingless slice motor", IEEE/ASME Transactions on Mechatronics, 2018, vol. 23, no. 6, pp. 29632967.

[10] P. Pfister and Y. Perriard, "Very High Speed Slotless Permanent Magnet Motors, Analytical Modeling, Optimization, Design and Torque Measurement Methods", IEEE Transactions on Industrial Electronics, 2010, vol. 57, no. 1, pp. 296303.

[11] D. Steinert, T. Kolar, and J. W. Nussbaumer, "Slotless Bearingless Disk Drive for High-Speed and High-Purity Applications", IEEE Transactions on Industrial Electronics, 2014, vol. 61, no. 11, pp. 59745986.

[12] Y. N. Zhilichev, "Analytic solutions of magnetic field problems slotless permanent magnet machines", COMPEL - The international journal for computation and mathematics electrical and electronic engineering, 2000, vol. 19, no. 4, pp. 940955.

[13] A. Tessarolo, M. Bortolozzi, and C. Bruzzese, "Explicit Torque and Back EMF Expressions for Slotless Surface Permanent Magnet Machines with Different Magnetization Patterns", IEEE Transactions on Magnetics, 2016, vol. 52, no. 8.

[14] X. Wang, S. Yan, X. Zhang et al, "The Rotor Topology of Slotless Permanent-Magnet Brushless DC Motor", International Conference on Electrical Machines and Systems, Incheon, South Korea, October 2010.

[15] F. Luise, A. Tessarolo, F. Agnolet et al, "Design Optimization and Testing of High-Performance Motors: Evaluating a Compromise Between Quality Design Development and Production Costs of a Halbach-Array PM Slotless Motor", IEEE Industry Applications Magazine, 2016, vol. 22, no. 6, pp. 19??32.

[16] A. Yoon, X. Yi, J. Martin et al, "A High-Speed, High-Frequency, Air-Core PM Machine for Aircraft Application", 2016 IEEE Power and Energy Conference at Illinois (PECI), Champaign, IL, USA, February 2016, pp. 14.

[17] M. S. Islam, I. Husain, and R. Mikail, "Slotless Lightweight Motor for Drone Applications", 2017 IEEE Energy Conversion Congress and Exposition (ECCE), Cincinnati, OH, USA, October 2017, pp. 50415048 .

[18] Z. Q. Zhu, Z. P. Xia, D. Howe et al, "Reduction of cogging force slotless linear permanent magnet motors", IEE Proceedings Electric Power Applications, 1997, vol. 144, no. 4, pp. 277282.

[19] X. Z. Huang, J. Li, Q. Tan et al, "Design Principles of a Phase-Shift Modular Slotless Tubular Permanent Magnet Linear Synchronous Motor With Three Sectional Primaries and Analysis of Its Detent Force", IEEE Transactions on Industrial Electronics, 2018, vol. 65, no. 12, pp. 93469355.

[20] P. Jalali, S. T. Boroujeni, and N. Bianchi, "Analytical Modeling of Slotless Eccentric Surface-Mounted PM Machines Using a Conformal Transformation", IEEE Transactions on Energy Conversion, 2017, vol. 32, no. 2, pp. 658666

[21] Z. Q. Zhu, D. Howe, and C. C. Chan, "Improved Analytical Model for Predicting the Magnetic Field Distribution Brushless Permanent-Magnet Machines", IEEE Transactions on Magnetics, 2002, vol. 38, no. 1, pp. 229238.

[22] D. Ishak, Z. Q. Zhu and D. Howe, "Unbalanced Magnetic Forces Permanent Magnet Brushless Machines with Diametrically Asymmetric Phase Windings", 40th IAS Annual Meeting, Hong Kong, October 2005, vol. 2, pp. 10371043.

[23] M. Markovic and Y. Perriard, "Simplified Design Methodology for a Slotless Brushless DC Motor", IEEE Transactions on Magnetics, 2006, vol. 42, no. 12, pp. 38423846.

[24] W. Cheng, Y. Sun, L. Yu et al, "Analytical solution to magnetic field distribution of a parallel magnetised rotor with cylindrical or ring-type permanent magnet", IET Electric Power Applications, 2014, vol. 9, no. 6, pp. 429437.

25] Y. Li, Q. Lu, Z. Q. Zhu et al, "Analytical Synthesis of Air-Gap Field Distribution Permanent Magnet Machines With Rotor Eccentricity by Superposition Method", IEEE Transactions on Magnetics, 2015, vol. 51, no. 11.

[26] W. Q. Chu and Z. Q. Zhu, "On-Load Cogging Torque Calculation Permanent Magnet Machines", IEEE Transactions on Magnetics, 2013, vol. 49, no. 2, pp. 29822989.

[27] L. Zhu, S. Z. Jiang, Z. Q. Zhu et al, "Analytical Methods for Minimizing Cogging Torque Permanent-Magnet Machines", IEEE Transactions on Magnetics, 2009, vol. 45, no. 4, pp. 20232031.

[28] O. Wallmark, P. Meier, and F. Kjellqvist, "Analysis of axial leakage high-speed slotless PM motors for industrial hand tools", IEEE Transactions on Industry Applications, 2009, vol. 45, no. 5, pp. 18151820 .

[29] D. Howe and Z. Q. Zhu, "The Influence of Finite Element Discretisation on the Prediction of Cogging Torque Permanent Magnet Excited Motors", IEEE Transactions on Magnetics, 1992, vol. 28 , no. 2 , pp. 10801083 .

30] S. H. Won and J. Lee, "BLDC spindle motor cogging torque calculation with the moving material method the finite element method", IEEE International Magnetics Conference (INTERMAG), Nagoya, Japan, April 2005.

Received 19 April 2020

Mario Vukotić received the MSc and PhD degree in electrical engineering from University of Ljubljana in 2012 and 2017, respectively. He is currently Researcher at the Laboratory of Electrical Machines, Department of Mechatronics, Faculty of Electrical Engineering, Ljubljana. His research work covers the areas of design, analysis and optimization of electrical machines, studying the different physical phenomena (electromagnetic, thermal and mechanical) in electrical machines as well as the development of various custom software tools for calculation of properties of electrical machines.

Danijel Rodić received the MSc degree in electrical engineering from University of Ljubljana in 2014. He is currently part of the R\&D department in company Domel. Focus of his work is developing and calculating electrical motors, mainly those with electronically commutated motors.

Boris Benedičič received the $\mathrm{MSc}$ and $\mathrm{PhD}$ degree in electrical engineering from University of Ljubljana in 1999 and 2004, respectively. He is currently Assistant R\&D Director in company Domel. His area of research includes electrical motors construction.

Damijan Miljavec received the MSc and $\mathrm{PhD}$ degree in electrical engineering from University of Ljubljana, Slovenia in 1996 and 1999, respectively. From 1996 he is employed at the Faculty of electrical engineering. He was elected as full professor in year 2014. In the field of research work he is mainly involved in numerical modeling and analysis of electromagnetic structures, design of new types of electrical machines, calculation of magnetic and thermal fields, introduction of new materials and measurement methods in the area of electrical machines. 